\title{
Maternal-fetal prognosis of obstetric emergencies at the maternity ward of the Mamou regional hospital
}

\author{
B. A. Diallo ${ }^{1 *}$, O. H. Bah ${ }^{1}$, M. S. Barry ${ }^{2}$, I. Conté ${ }^{1}$
}

\begin{abstract}
${ }^{1}$ Department of Gynecology Obstetric, University Gamal Abdel Naser of Conakry, Guinea
${ }^{2}$ Department of Paediatrics, University Gamal Abdel Naser of Conakry, Guinea
\end{abstract}

Received: 04 December 2019

Accepted: 16 December 2019

\author{
*Correspondence: \\ Dr. B. A. Diallo, \\ E-mail: boubacardiallo@gmail.com
}

Copyright: () the author(s), publisher and licensee Medip Academy. This is an open-access article distributed under the terms of the Creative Commons Attribution Non-Commercial License, which permits unrestricted non-commercial use, distribution, and reproduction in any medium, provided the original work is properly cited.

\begin{abstract}
Background: Pregnant women may be at risk of unpredictable obstetric complications such as: bleeding, dystocia, acute fetal suffering, pre-eclampsia and eclampsia. This maternal-fetal prognosis of obstetric emergencies is influenced by factors that are most often related to complications that alter the course or outcome of a pregnancy and require prompt care. The objectives of this study are to analyze the factors that influence the maternal-fetal prognosis of obstetric emergencies; determine their frequency, describe the clinical profiles of patients and evaluate the maternal-fetal prognosis.

Methods: The study was conducted at the Mamou Regional Hospital. It was a 6-month quantitative, descriptive and analytical study, from July $1^{\text {st }}$ to December $31^{\text {st }}$, 2016, including all parturient women whose term is greater than or equal to 28 weeks of amenorrhoea.

Results: The study covered 377 obstetric emergencies out of a total of 1273 deliveries, or 29.61\%. Factors influencing the prognosis were: young age, parity, unfavorable socio-economic conditions and difficult baseline conditions. The main obstetric emergencies recorded were acute fetal suffering, disproportion and narrowed pelvis. The dominant mode of delivery was caesarean section with a frequency of $89.65 \%$. Maternal lethality is $3.44 \%$ and fetal lethality is $5.14 \%$.

Conclusions: Obstetric emergency is a frequent situation where better management would improve the prognosis of the mother and fetus.
\end{abstract}

Keywords: Maternal fetal prognosis, Nature of emergencies, Obstetrical emergencies

\section{INTRODUCTION}

Pregnant women are at risk of obstetric complications that can be fatal and often unpredictable. Among them: hemorrhages, dystocias, acute fetal suffering, preeclampsia and eclampsia are the most common. Prenatal screening does not identify all women who will experience complications. The determinants of maternalfetal prognosis in obstetric emergencies are the set of elements that define the course or outcome of a pregnancy, related to complications requiring rapid care. ${ }^{1}$
In 2013, according to the World Health Organization (WHO), 289,000 women died during or after pregnancy or childbirth as a result of obstetric complications. More than $30 \%$ of these deaths occur in Africa and $7 \%$ in Latin America; in contrast, in developed countries, 6,000 deaths are recorded per year. ${ }^{1,2}$ In West and Central Africa, complications of pregnancy, childbirth and childbirth are the leading cause of maternal and neonatal mortality. ${ }^{3}$ In East and West Africa, the figures are the highest since in some countries more than 1000 women per 100,000 live births die. ${ }^{4}$ 
In Northern Europe the figures are lower, ranging from 0 to 11 maternal deaths per 100,000 live births. ${ }^{5}$ In Guinea, the maternal mortality rate in 2012 was 610 per 100,000 live births. ${ }^{6}$ The maternal morbidity rate is an indicator that measures the extent of the problem and the capacity of different health systems to meet obstetric needs. It has been shown that $69 \%$ of these deaths are preventable through anesthesia and resuscitation measures. ${ }^{7}$

For better management of obstetric complications, more research should be conducted to improve the quality of care from health services to the community level. In order to reduce maternal and fetal mortality and morbidity, particular attention should be paid to the factors that influence the maternal and fetal prognosis of obstetric emergencies, hence the importance of conducting this study.

The objectives of this study are to analyze the factors that influence the maternal-fetal prognosis of obstetric emergencies; determine their frequency, describe the clinical profiles of patients and evaluate the maternalfetal prognosis.

\section{METHODS}

The gynecology-obstetrics department of the Mamou regional hospital was used as the framework for the study. It was a cross-sectional, descriptive and analytical study over a period of 6 months, from July $1^{\text {st }}$ to December $31^{\text {st }}, 2016$, with a minimum sample size of 355.

\section{Inclusion criteria}

- All parturient women admitted to the delivery room, whose term is greater than or equal to 28 weeks of amenorrhoea and whose care has been provided in the ward, have been selected.

\section{Exclusion criteria}

- Patients with a term of less than 28 weeks of amenorrhoea, cases of in-utero death, those whose management did not take place in the unit were excluded from the study.

\section{Statistical analysis}

The data were entered and analyzed using EPI INFO version 6 software. The statistical test used is Chi 2, with a significance level set at $\mathrm{P}<0.05$.

\section{RESULTS}

\section{Frequency of obstetric emergencies}

During this study we recorded 377 obstetric emergencies out of a total of 1273 deliveries, representing a frequency of $29.61 \%$.
Table 1: Socio-demographic characteristics and obstetric history of the 377 obstetric emergencies.

\begin{tabular}{|c|c|c|c|c|c|c|}
\hline \multicolumn{7}{|l|}{ Age } \\
\hline Age group & \multicolumn{4}{|c|}{ Number of employees } & \multicolumn{2}{|l|}{$\%$} \\
\hline $15-19$ & \multicolumn{3}{|c|}{91} & & \multicolumn{2}{|c|}{$24.14 \%$} \\
\hline $20-24$ & \multicolumn{3}{|c|}{83} & & \multicolumn{2}{|c|}{$22.02 \%$} \\
\hline $25-29$ & \multicolumn{3}{|c|}{89} & & \multicolumn{2}{|c|}{$23.61 \%$} \\
\hline $30-34$ & \multicolumn{3}{|c|}{59} & & \multicolumn{2}{|c|}{$15.65 \%$} \\
\hline$>34$ & \multicolumn{3}{|c|}{55} & & \multicolumn{2}{|c|}{$14.59 \%$} \\
\hline \multicolumn{7}{|c|}{ Average age $=25.51$ years with extremes from $15-40$ years } \\
\hline \multicolumn{7}{|c|}{ Educational level } \\
\hline No level & \multicolumn{3}{|c|}{256} & \multicolumn{3}{|c|}{67.9} \\
\hline Primary & \multicolumn{3}{|c|}{58} & \multicolumn{3}{|c|}{15.4} \\
\hline Secondary & \multicolumn{3}{|c|}{47} & \multicolumn{3}{|c|}{12.5} \\
\hline Superior & \multicolumn{3}{|c|}{16} & \multicolumn{3}{|c|}{4.2} \\
\hline Total & \multicolumn{2}{|c|}{377} & & \multicolumn{3}{|c|}{$100 \%$} \\
\hline Parity & $\begin{array}{l}15- \\
19\end{array}$ & $\begin{array}{l}20- \\
24\end{array}$ & $\begin{array}{l}25- \\
29\end{array}$ & $\begin{array}{l}30- \\
34\end{array}$ & $\begin{array}{l}\geq \\
35\end{array}$ & Total \\
\hline Nullipare & 75 & 31 & 15 & 2 & 0 & 123 \\
\hline Paucipare & 3 & 20 & 48 & 23 & 9 & 103 \\
\hline Primipare & 13 & 31 & 17 & 6 & 0 & 67 \\
\hline Multipare & 0 & 1 & 9 & 21 & 20 & 51 \\
\hline $\begin{array}{l}\text { Large } \\
\text { multipare }\end{array}$ & 0 & 0 & 0 & 7 & 26 & 33 \\
\hline Total & 91 & 83 & 89 & 59 & 55 & 377 \\
\hline
\end{tabular}

$\chi^{2}=369.90, \mathrm{ddl}=16, \mathrm{P}=0.001$

Table 2: Mode of admission of emergencies term of pregnancy on admission.

\begin{tabular}{|lll|}
\hline Mode of admission & Number of employees & $\%$ \\
\hline Coming from herself & 184 & 48.8 \\
\hline Evacuee / referee & 193 & 51.2 \\
\hline Total & $\mathbf{3 7 7}$ & $\mathbf{1 0 0}$ \\
\hline \multicolumn{2}{|c|}{ Term of pregnancy } & on admission \\
\hline$<37$ SA & 36 & 9.54 \\
\hline $37-42$ & 318 & 84.35 \\
\hline$>42$ & 23 & 6.10 \\
\hline Total & $\mathbf{3 7 7}$ & $\mathbf{1 0 0 \%}$ \\
\hline
\end{tabular}

Table 3: Nature of the 377 obstetric emergencies.

\begin{tabular}{|lll|}
\hline Urgency & $\begin{array}{l}\text { Number of } \\
\text { employees }\end{array}$ & $\begin{array}{l}\text { Frequency } \\
(\%)\end{array}$ \\
\hline Acute fetal distress & 92 & 24.13 \\
\hline Disproportion & 87 & 23.07 \\
\hline Shrunk pelvis & 58 & 15.38 \\
\hline Dystocic presentation & 61 & 16.18 \\
\hline $\begin{array}{l}\text { Third trimester } \\
\text { hemorrhage }\end{array}$ & 36 & 9.55 \\
\hline $\begin{array}{l}\text { Severe eclampsia/pre- } \\
\text { eclampsia }\end{array}$ & 22 & 5.84 \\
\hline PMTCT & 8 & 2.12 \\
\hline Others & 17 & 4.5 \\
\hline Total & $\mathbf{3 7 7}$ & $\mathbf{1 0 0}$ \\
\hline
\end{tabular}


Table 4: Management upon admission of obstetrical emergencies.

\begin{tabular}{|lll|} 
Decision & $\begin{array}{l}\text { Number of } \\
\text { employees }\end{array}$ & $\begin{array}{l}\text { Frequency } \\
(\%)\end{array}$ \\
\hline Venous route + solutes & 375 & 99.46 \\
\hline Caesarean section & 338 & 89.65 \\
\hline Transfusion & 77 & 20.42 \\
\hline Monitoring for childbirth & 33 & 8.75 \\
\hline Oxytocic infusion & 23 & 6.1 \\
\hline Laparotomy & 14 & 3.71 \\
\hline
\end{tabular}

Table 5: Maternal and fetal morbidity related to obstetric emergencies.

\begin{tabular}{|lll|}
\hline Maternal morbidity & $\begin{array}{l}\text { Number of } \\
\text { employees }\end{array}$ & $\begin{array}{l}\text { Frequency } \\
(\%)\end{array}$ \\
\hline With complication & 131 & 34.75 \\
\hline No complication & 246 & 65.25 \\
\hline Anemia & 81 & 21.49 \\
\hline HRP & 18 & 4.77 \\
\hline Infection & 10 & 2.65 \\
\hline Eclampsia & 7 & 1.86 \\
\hline Others & 2 & 0.53 \\
\hline Fetal morbidity & Effective & Frequency (\%) \\
\hline SFA & 91 & 23.4 \\
\hline Respiratory distress & 71 & 18.3 \\
\hline Prematurity & 14 & 3.6 \\
\hline Malformation & 3 & 0.7 \\
\hline MFIS & 1 & 0.3 \\
\hline No complication & 189 & 48.58 \\
\hline
\end{tabular}

Table 6: Maternal and fetal lethality and their causes.

\begin{tabular}{|lll|}
\hline Maternal lethality & $\begin{array}{c}\text { Number of } \\
\text { employees }\end{array}$ & Frequency (\%) \\
\hline Alive & 364 & 96.55 \\
\hline Deceased & 13 & 3.44 \\
\hline Total & $\mathbf{3 7 7}$ & $\mathbf{1 0 0}$ \\
\hline Cause of maternal deaths & \\
\hline Anemia & 10 & 76.92 \\
\hline Eclampsia & 2 & 15.38 \\
\hline HRP & 1 & 7.69 \\
\hline Total & $\mathbf{1 3}$ & $\mathbf{1 0 0}$ \\
\hline Fetal lethality and their causes & \\
\hline Lethality & Effective & Frequency $(\boldsymbol{\%})$ \\
\hline Living & 369 & 94.86 \\
\hline deceased & 20 & 5.14 \\
\hline Total & $\mathbf{3 8 9}$ & $\mathbf{1 0 0}$ \\
\hline Causes of death of & newborn & \\
\hline Cause of death & Effective & Frequency $(\boldsymbol{\%})$ \\
\hline Respiratory distress & 10 & 50 \\
\hline SFA & 6 & 30 \\
\hline Prematurity & 4 & 20 \\
\hline Total & $\mathbf{2 0}$ & $\mathbf{1 0 0}$ \\
\hline
\end{tabular}

\section{Sociodemographic characteristics and obstetric history}

The average age of our patients was 25.51 years with extremes of 15 and 40 years.

The 15-19 age group was the most affected with $24.14 \%$.

\section{DISCUSSION}

\section{Frequency}

During this study we recorded 377 obstetric emergencies out of a total of 1273 deliveries, representing a frequency of $29.61 \%$. Our proportion is close to the $31.8 \%$ found by Tchaou BA et al, at Parakou University Hospital in Benin, but higher than the $21.7 \%$ found in West Amansie District in the Ashanti region of Ghana. ${ }^{2,8}$

\section{Sociodemographic characteristics and obstetrics history}

Age

The average age of our patients was 25.51 years with extremes of 15 and 40 years. The sample was dominated by women in the $15-19$ age group with $24.14 \%$ (Table 1 ).

Saizonou $\mathbf{J}$ et al, in analysing the management of obstetric emergencies in referral maternity hospitals in Benin, find that the 20-34 age group was the most represented with an average age of 26.7 years. ${ }^{9}$

\section{Education level}

The results of the study showed that nearly $2 / 3$ of obstetric emergencies, or $67.9 \%$, were uneducated patients, or those who stopped studies at the primary level, or $15.4 \%$. This result is significantly higher than the $46 \%$ of women who have not attended school, found in Benin by Saizonou et al (Table 1). ${ }^{9}$

\section{Parity}

The study of this parameter shows that $32.6 \%$ of emergencies were nulliparous, $27.3 \%$ of primiparous (Table 1). This cross-tabulation result at parturient age showed a statistically significant relationship with $\mathrm{p}=$ 0.001 . Our is less than the $48.7 \%$ of primiparous women found in Rwanda by Patrick $\mathrm{S}$ et al. ${ }^{10}$

\section{Admission method}

We found that half of the emergencies were evacuees, $51.2 \%$ compared to $48.8 \%$ (Table 2 ).

\section{Natures of obstetric emergencies}

The main obstetric emergencies encountered are: acute fetal suffering (24.13\%), fetal disproportions (23.07), narrow pelvis $(15.38 \%), 3^{\text {rd }}$ trimester hemorrhages $(9.5 \%)$ 
(Table 3). In contrast, in Burkinafaso, and Gabon Ouattara A and Mayi-Tsonga, find that the main reason for transferring obstetric emergencies was pre-eclampsia and eclampsia. ${ }^{11,12}$

\section{Management upon admission of obstetrical emergencies}

The conduct depended on several factors, including the end of the pregnancy, the diagnosis and the patient's condition at admission. In our series, $89.65 \%$ of patients delivered by cesarean section for a maternal indication (maternal disproportion (maternal-fetal, narrowed pelvis, genital hemorrhage, or hypertension) or fetal (FAS, prematurity) and $6.63 \%$ by the lower route.

A total $20.42 \%$ of patients had been transfused due to severe anemia and $99.46 \%$ of patients had had vascular filling (Table 4).

In a study conducted in Beni, Tchaou BA et al reported $53.4 \%$ of vaginal deliveries and $46.6 \%$ of cesarean deliveries, $17.5 \%$ of patients had been transfused for severe anemia and $60.2 \%$ had received vascular filling. ${ }^{2}$

\section{Maternal and fetal morbidity related to obstetric emergencies}

Complications occurred in $34.75 \%$ of women admitted urgently. The main maternal complications were anemia $(21.49 \%)$, retroplacental hematoma $(4.77 \%)$, and postpartum infections (2.65). We recorded $20.85 \%$ of newborns in respiratory distress and $3.6 \%$ of prematurity. Cross-referenced to maternal age, we found that fetal morbidity is more frequent in the 15-19 age group and respiratory distress is the most common complication with a statistically significant relationship $(\mathrm{p}=0.002)$ (Table 5).

In Cameroon, Ethienne et al report $37.3 \%$ prematurity and $17.9 \%$ neonatal asphyxia. ${ }^{13}$ In a study conducted in Benin by Blaise AT et al, the main maternal complications found were hypertensive flare-up $(21.1 \%)$, hyperthermia (12.3\%), clinical anemia (11.2\%), convulsive seizures $(1.4 \%)^{2}$

\section{Maternal and neonatal lethality and their causes}

We recorded $3.44 \%$ of maternal deaths $(n=13)$. The causes of death were anemia ten cases $(76.92 \%)$, eclampsia two cases $(15.38 \%)$, and postpartum hemorrhage one case $(7.69 \%$ ) (Table 6).

Benimana et al, report that previous cesarean delivery and prolonged labor were associated with $24 \%$ and $13.2 \%$ maternal and neonatal mortality, respectively. ${ }^{14}$

We registered 389 newborns, of whom 20 perinatal deaths were observed, or $5.14 \%$. Most of these deaths occurred in perpartum $70 \%(\mathrm{n}=14)$ and $30 \%$ during the first week of life. The main causes were respiratory distress $(50 \%)(p=0.002)$, acute fetal suffering $(30 \%)$ and prematurity (20\%). The causes of neonatal lethality are in agreement with those of Etienne B et al who found $48.1 \%$ by severe neonatal asphyxia. ${ }^{13}$

Limitations of this study was to the low capacity of the service for the timely hospitalization of patients, the failure to carry out certain laboratory tests whose results would improve the management of obstetric emergencies. Consent: before the study was carried out, we obtained the agreement of the administrative authorities of the service, the patients gave their consent to participate in the study, confidentiality was respected throughout the data collection procedure and the results were used for strictly scientific purposes.

\section{CONCLUSION}

Obstetric emergency is a frequent situation where better management would improve the prognosis of the mother and fetus.

\section{Funding: No funding sources Conflict of interest: None declared}

Ethical approval: The study was approved by the Institutional Ethics Committee

\section{REFERENCES}

1. Coulibaly. D Clinical epidemiological study of obstetric emergencies at the reference health center of commune IV about 293 cases. Doctoral thesis in Medicine, University of Bamako; 2008.

2. Tchaou BA, Hounkponou NF, Kabibou S, Eugène ZM. Obstetrical emergencies at PARAKOU University Hospital in Benin: clinical, therapeutic and evolutionary aspects. Eur Scient J. 2015;11:26072 .

3. Blaise AT, Nouessewa FMH, Kabibou S, Eugène Z, Martin C. Obstetric emergencies at the parakou university hospital in benin: clinical, therapeutic and progressive aspects. Eu Scient J. 2015;11:9.

4. Dagnon OZ. Problem of the management of obstetric emergencies at the Bougouni reference health center. Doctoral thesis in Medicine, University of Bamako; 2008.

5. Dissa L. Epidemio-clinical study of obstetric emergencies at the Reference Health Center of the Commune V. Doctoral thesis in Medical, University of Bamako; 2005.

6. WHO: World health statistics of the world health organization (WHO 2013). 2013;7:1-172.

7. Groof D, Harouna Y, Bossyns S. application of the BONC method in the community of Niamey. Niger; 1999.

8. Nuamah GB, Agyei-Baffour P, Akohene KM, Boateng D, Dobin D, Addai-Donkor K. Incentives to yield to obstetric referrals in deprived areas of the Amansie West district in the Ashanti region of Ghana. Int J Equity Health. 2016;15(1):117-1186. 
9. Saizonou J, Godin I, Ouendo EM, Zerbo R, Dujardin B. The quality of care for obstetric emergencies in the reference maternities in Benin: The point of view of Beautiful Escapes and their expectations. Trop Med Int Health. 2006;2(5):672-80.

10. Smeele P, Kalisa R, Elteren M, Roosmalen J, van den Akker T. Birth preparedness and complication readiness among pregnant women admitted in a rural hospital in Rwanda. BMC Preg Childbirth. 2018;18(190):1-7.

11. Ouattara A, Ouedraogo CM, Ouédraogo A, Lankoande J. Emergency and non-urgent transfers of obstetric patients to the Yalgado Ouédraogo University Hospital Center (UHC-YO) in Ouagadougou. Med Sante Trop. 2015;25(4):403-7.

12. Mayi-Tsonga S, Meye JC, Tagne A, Ndombi I, Diallo T, Oksana L, et al. Audit of severe obstetric morbidity (near miss) in Gabon. Health Notebooks; 2007;17(2):111-5.
13. Belinga E, Foumane P, Dohbit SJ, Ngo Um EM, Kiyeck DK, Mboudou ET. Prognosis of obstetric references at the Gyneco-Obstetric and Pediatric Hospital of Yaoundé (HGOPY). Pan African Med J. 2017;28:301.

14. Benimana, Maria. Small; Stephen Rulisa: Preventability of maternal near miss and mortality in Rwanda: A case series from the University Teaching Hospital of Kigali (CHUK) Christophe. Plos-One. 2018;13(6):1-11.

Cite this article as: Diallo BA, Bah $\mathrm{OH}$, Barry MS, Conté I. Maternal-fetal prognosis of obstetric emergencies at the maternity ward of the Mamou regional hospital. Int J Reprod Contracept Obstet Gynecol 2020;9:225-9. 